Corrigendum

\title{
Corrigendum to "Observer-Based Sliding Mode Control for Stabilization of a Dynamic System with Delayed Output Feedback"
}

\author{
Bo Wang, ${ }^{1,2}$ Peng Shi, ${ }^{3,4}$ Hamid Reza Karimi, ${ }^{5}$ and Cheng Chew Lim ${ }^{3}$ \\ ${ }^{1}$ School of Electrical and Information Engineering, Xihua University, Chengdu 610096, China \\ ${ }^{2}$ School of Applied Mathematics, University Electronic Science and Technology of China, Chengdu 610054, China \\ ${ }^{3}$ School of Electrical and Electronic Engineering, The University of Adelaide, Adelaide, SA 5005, Australia \\ ${ }^{4}$ College of Engineering and Science, Victoria University, Melbourne, VIC 8001, Australia \\ ${ }^{5}$ Department of Engineering, Faculty of Engineering and Science, University of Agder, 4898 Grimstad, Norway \\ Correspondence should be addressed to Cheng Chew Lim; cheng.lim@adelaide.edu.au
}

Received 23 October 2016; Accepted 25 October 2016

Copyright (c) 2016 Bo Wang et al. This is an open access article distributed under the Creative Commons Attribution License, which permits unrestricted use, distribution, and reproduction in any medium, provided the original work is properly cited.

In the article titled "Observer-Based Sliding Mode Control for Stabilization of a Dynamic System with Delayed Output Feedback" [1] the order of the first and second affiliations was incorrect. The correct order of affiliations is shown above.

\section{References}

[1] B. Wang, P. Shi, H. R. Karimi, and C. Lim, "Observer-based sliding mode control for stabilization of a dynamic system with delayed output feedback," Mathematical Problems in Engineering, vol. 2013, Article ID 537414, 6 pages, 2013. 


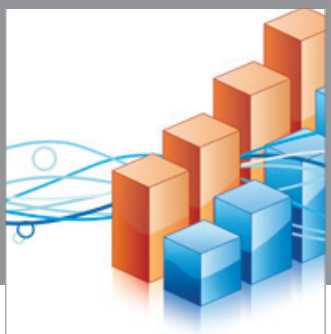

Advances in

Operations Research

vatem alat4

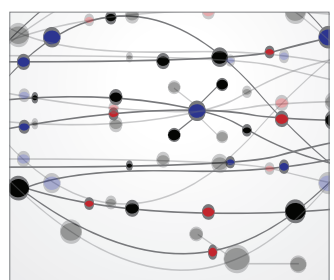

\section{The Scientific} World Journal
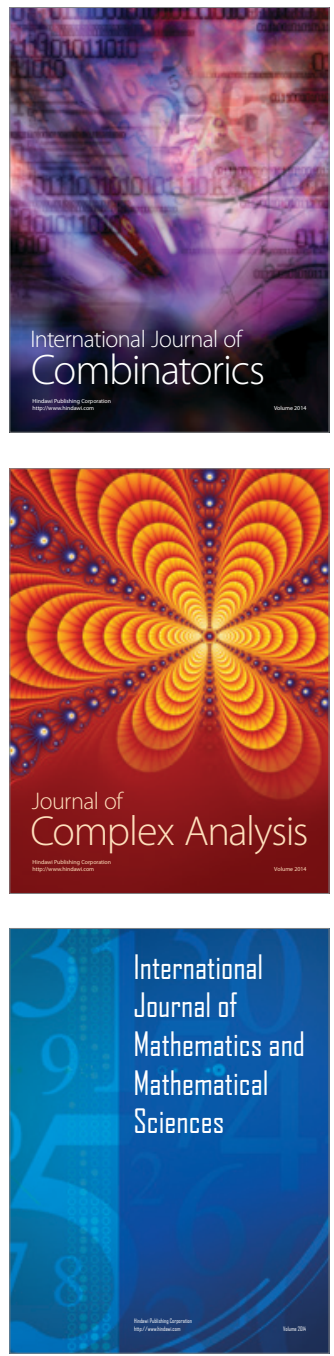
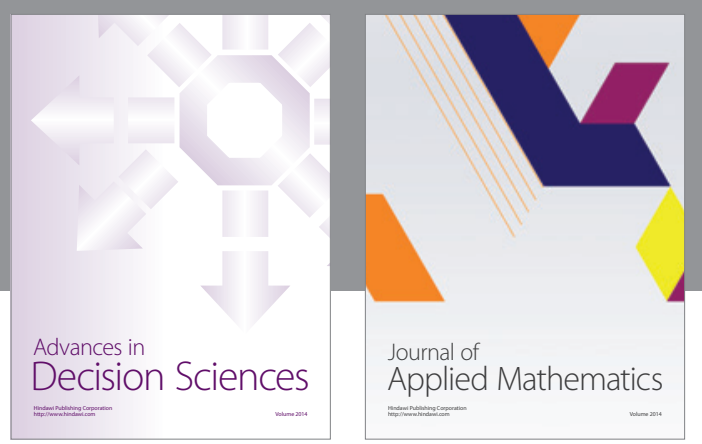

Algebra

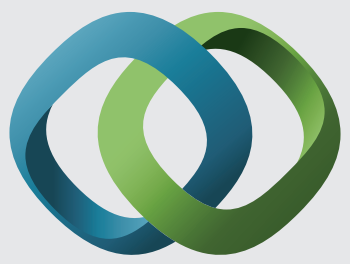

\section{Hindawi}

Submit your manuscripts at

http://www.hindawi.com
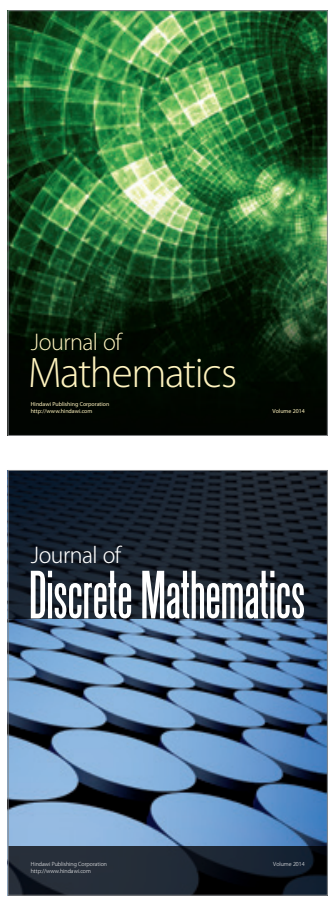

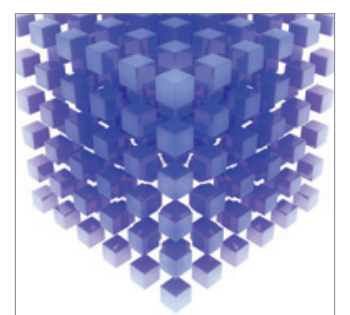

Mathematical Problems in Engineering
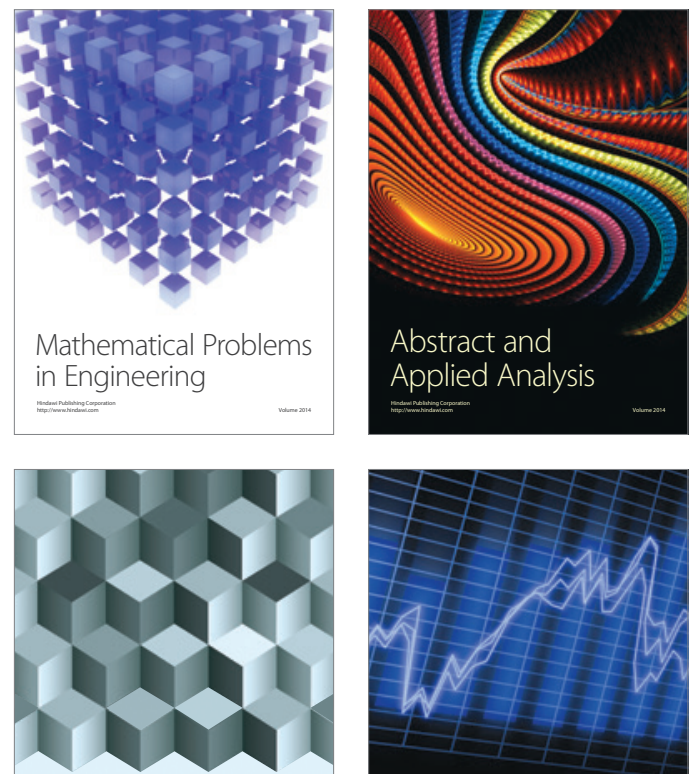

Journal of

Function Spaces

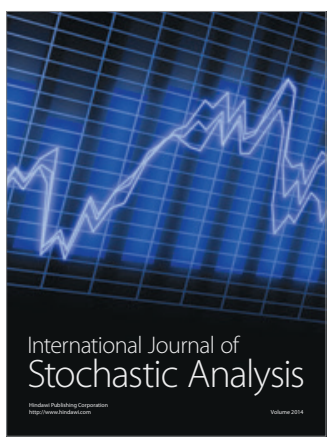

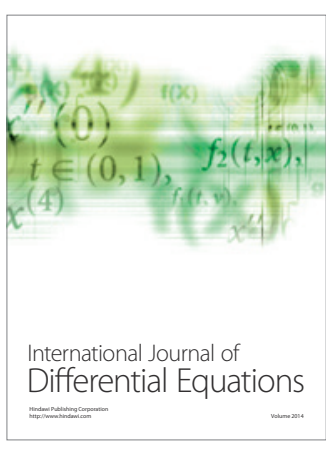
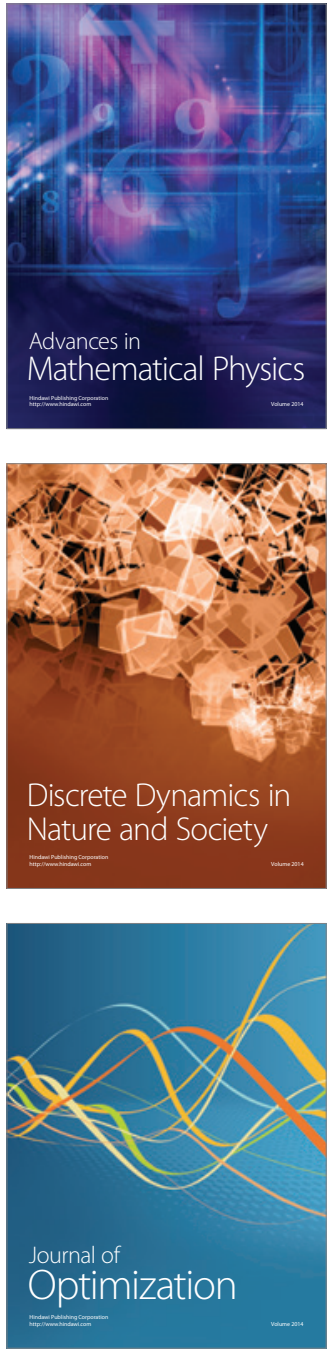